\begin{tabular}{|c|l|}
\hline Title & $\begin{array}{l}\text { Molecular structure and conformation of diethy Imethylamine determined by gas electron diffraction and vibrational } \\
\text { spectroscopy combined with theoretical calculations }\end{array}$ \\
\hline Author(s) & Takeuchi, Hiroshi; Ito, Masaki; Egawa, Toru \\
\hline Citation & $\begin{array}{l}\text { Journal of Molecular Structure, 840(1-3), 107-113 } \\
\text { https://doi.org/10.1016/.molstruc.2006.11.027 }\end{array}$ \\
\hline Issue Date & $2007-09$-17 \\
\hline Doc URL & http:/hdl.handle.net/2115/28245 \\
\hline Type & article (author version) \\
\hline File Information & JMS840-1-3.pdf \\
\hline
\end{tabular}

Instructions for use 


\title{
Molecular structure and conformation of diethylmethylamine determined by gas electron diffraction and vibrational spectroscopy combined with theoretical calculations
}

\section{Hiroshi Takeuchi,* Masaki Ito, Toru Egawa}

Division of Chemistry, Graduate School of Science, Hokkaido University, Sapporo 060-0810, Japan

* Corresponding author. Tel: +81-11-706-3533. Fax: +81-11-706-4924. E-mail: takehi@sci.hokudai.ac.jp

\begin{abstract}
We have investigated the molecular structure and conformation of diethylmethylamine, $\mathrm{C}(4) \mathrm{H}_{3} \mathrm{C}(2) \mathrm{H}_{2} \mathrm{~N}(1)\left[\mathrm{CH}_{3}\right] \mathrm{C}(3) \mathrm{H}_{2} \mathrm{C}(5) \mathrm{H}_{3}$, by gas electron diffraction and vibrational spectroscopy with the aid of theoretical calculations. Diffraction data are consistent with a conformational mixture of $35(14) \% t t+27(14) \% g^{+} t+20(17) \%$ $\mathrm{g}^{-} \mathrm{t}+18(23) \% \mathrm{~g}^{+} \mathrm{g}^{+}$where the numbers in parentheses denote three times the standard errors $(3 \sigma)$. Normal-coordinate analysis based on B3LYP/6-311+G $\mathrm{G}^{* *}$ calculations supports the existence of the four conformers. The dihedral angle $\phi_{1}(\mathrm{C} 4 \mathrm{C} 2 \mathrm{~N} 1 \mathrm{C} 3)$ (= $\left.-\phi_{2}(\mathrm{C} 5 \mathrm{C} 3 \mathrm{~N} 1 \mathrm{C} 2)\right)$ of the $\mathrm{tt}$ conformer was $170(4)^{\circ}$ whereas the $\phi_{1}$ and $\phi_{2}$ values of the other conformers were fixed at the B3LYP/6-311++G(2df,p) values: $72.4^{\circ}$ and $-163.3^{\circ}$ for the $\mathrm{g}^{+} \mathrm{t},-66.0^{\circ}$ and $-158.2^{\circ}$ for the $\mathrm{g}^{-} \mathrm{t}$, and $60.3^{\circ}$ and $63.5^{\circ}$ for the $\mathrm{g}^{+} \mathrm{g}^{+}$. Average values of the structural parameters $\left(r_{\mathrm{g}} / \AA\right.$ and $\left.\angle_{\alpha}{ }{ }^{\circ}\right)$ with $3 \sigma$ are: $\langle r(\mathrm{~N}-\mathrm{C})>=1.462(2)$,
\end{abstract}


$<r(\mathrm{C}-\mathrm{C})>=1.523(3), \quad\langle r(\mathrm{C}-\mathrm{H})>=1.113(2), \quad<\angle \mathrm{CNC}>=111.6(5), \quad<\angle \mathrm{NCC}>=$ 114.5(5), $<\angle \mathrm{NCH} / \angle \mathrm{CCH}_{\mathrm{Me}}>=110.6(5)$.

Keywords: Diethylmethylamine; molecular structure; conformation; electron diffraction; vibrational spectroscopy.

\section{Introduction}

Amines with at least one ethyl group exhibit conformational flexibility. To understand it, gas-phase molecular structures and conformations of ethylamine [1], methylethylamine [2,3] and dimethylethylamine [4-6] have been investigated by spectroscopic and diffraction methods. These studies indicate that the trans CNCC conformer is preferred to the gauche conformer. For more complicated amines with ethyl groups, diethylamine, triethylamine and $\mathrm{N}$-chloro- $\mathrm{N}$-ethylethanamine $\left(\mathrm{Et}_{2} \mathrm{NCl}\right)$, we have determined their molecular structures and conformations by gas electron diffraction (GED) combined with ab initio calculations [7, 8]. Two or more conformers were detected for each compound. In the present study, we have determined the molecular structure and conformation of diethylmethylamine (DEMA) by GED. The obtained results are compared with conformations of related amines.

Bushweller et al. [9] investigated conformation of DEMA by ${ }^{1} \mathrm{H}$ NMR spectroscopy with the aid of empirical force-field calculations. ${ }^{1} \mathrm{H}$ NMR spectra of DEMA, $\left(\mathrm{CH}_{3} \mathrm{CD}_{2}\right)_{2} \mathrm{NCH}_{3}$ and $\left(\mathrm{CD}_{3} \mathrm{CH}_{2}\right)_{2} \mathrm{NCH}_{3}$ were recorded in $\mathrm{CBrF}_{3}$ solution at temperatures of $100 \mathrm{~K}$ to $200 \mathrm{~K}$. Each of spectra measured at about $100 \mathrm{~K}$ was decomposed into two subspectra consisting of some lines. The authors assigned the major and minor subspectra (85\% and 15\%) to $t \mathrm{t} / \mathrm{g}^{+} \mathrm{t}$ and $\mathrm{g}^{-} \mathrm{t} / \mathrm{g}^{+} \mathrm{g}^{+}$families (see Fig. 1), respectively. In 
each family, conformation is easily converted.

IR and Raman spectra of DEMA in the solid, liquid and gas phases were studied by Crocker and Goggin [6]. Two conformers detected in the solid phase were suggested to be $t$ and $\mathrm{g}^{+} \mathrm{t}$. On the other hand, from the complexity of a vapor spectrum, they concluded that two or more conformers exist in the gas phase. Therefore, conformational analysis of DEMA is an open problem.

A few vibrational frequencies relating to $\mathrm{N}-\mathrm{C}$ stretching modes are reported by Crocker and Goggin [6] and IR spectra of the liquid are available from Ref. [10]. To perform vibrational and conformational analysis in more details, gas-phase IR spectra and FT-Raman spectra of the liquid have been measured in the present study. Furthermore, RHF, MP2 [11] and B3LYP $[12,13]$ calculations with various basis sets are carried out to obtain information on the structure, conformation and force field of DEMA. Since the B3LYP/6-311+G** calculations with wavenumber-linear scale factors provide reasonable estimate of vibrational frequencies [14], the density functional theory calculations at the same level are used to interpret vibrational spectra. Structural constraints in GED analysis are taken from results of B3LYP calculations with a larger basis set 6-311++G(2df,p).

\section{Experimental}

A commercial sample of DEMA (Aldrich) with a purity of $98 \%$ was used after distillation in vacuum. The experiments were made with an apparatus equipped with an $r^{3}$-sector [15] at two camera distances, $245.1 \mathrm{~mm}$ (short) and $490.2 \mathrm{~mm}$ (long). Diffraction patterns were recorded on $8 \times 8$ in. Kodak projector slide plates at room temperature $\left(24^{\circ} \mathrm{C}\right)$. The accelerating voltage was about $37 \mathrm{kV}$. The diffraction 
patterns of carbon disulfide were recorded after those of DEMA to determine the wavelength of incident electrons $\left(r_{\mathrm{a}}(\mathrm{C}-\mathrm{S})=1.5570 \AA \AA\right)[16]$. The plates were developed in Kodak Dektol developer diluted 1:1 for 4.5 min. Other experimental conditions are as follows: exposure times, $92 \mathrm{~s}$ (short) and $47 \mathrm{~s}$ (long); electron wavelengths, $0.06348 \AA$ (short) and $0.06373 \AA$ (long); sample pressure, 35 Torr; beam current, $2.4 \mu \mathrm{A}$; uncertainties of scale factor, $0.04 \%$.

Optical densities were measured with a microphotometer of double-beam autobalanced type. The average densities obtained at intervals of $0.5 \mathrm{~mm}$ were converted to total intensities [17], which were then divided by theoretical backgrounds to level total intensities. The leveled total intensities were obtained from four and two plates for short- and long-camera distances, respectively. They were averaged and used for data analysis. Elastic and inelastic scattering factors were taken from Ref. [18]. The leveled total intensities are deposited as supplementary data. The molecular scattering intensities and experimental radial distribution curve of DEMA are shown in Figs. 2 and 3, respectively.

Gas-phase IR spectra were measured at resolutions of $0.5 \mathrm{~cm}^{-1}$ by using a BOMEM DA 3.16 Fourier transform spectrometer at room temperature. In the measurement, a cell with $\mathrm{KBr}$ windows and a path of $10 \mathrm{~cm}$ was used. The FT-Raman spectra of liquid DEMA were recorded on the same spectrometer at $4 \mathrm{~cm}^{-1}$ resolution by using an Nd:YAG laser. No impurity was detected in these spectroscopic measurements.

\section{Structural Determination}

\subsection{Theoretical calculations}

Calculations were carried out using Gaussian 98 [19]. Geometries of the five 
conformers shown in Fig. 1 and $\mathrm{g}^{+} \mathrm{g}^{-}$conformer were optimized at the HF/6-31G ${ }^{* *}$ level with no symmetry restriction. The $\mathrm{g}^{+} \mathrm{g}^{-}$form converged to $\mathrm{tg}^{-}$form, the mirror image of $\mathrm{g}^{+} \mathrm{t}$. Therefore, for the five conformers except the $\mathrm{g}^{+} \mathrm{g}^{-}$conformer, further geometry optimization was carried out by MP2 [11] and B3LYP [12, 13] methods. MP2 calculations were performed with frozen-core approximation using 6-31G ${ }^{* *}$ and $6-311+\mathrm{G}^{* *}$ basis sets. For B3LYP method, we used three kinds of basis sets, $6-31 \mathrm{G}^{* *}$, $6-311+\mathrm{G}^{* *}$ and $6-311++\mathrm{G}(2 \mathrm{df}, \mathrm{p})$. Table 1 shows that relative energies of these conformers depend on the calculation method and basis set, whereas the order of the stability is consistent through all the calculations. The structures optimized at B3LYP/6-311++G(2df,p) level are listed in Table 2.

The populations of the $t \mathrm{t}, \mathrm{g}^{+} \mathrm{t}, \mathrm{g}^{-} \mathrm{t}, \mathrm{g}^{+} \mathrm{g}^{+}$and $\mathrm{g}^{-} \mathrm{g}^{+}$conformers were estimated from the energy differences listed in Table 1 . All the calculations suggest that the population of $\mathrm{g}^{-} \mathrm{g}^{+}$form is negligibly small $(\leq 0.5 \%)$. This is consistent with the results of vibrational analysis described in next section.

\subsection{Vibrational analysis}

Cartesian force constants of the five conformers were obtained from the B3LYP/6-311+G** calculations using Gaussian 98 [19] and were transformed into the quadratic force constants of local symmetry coordinates $f_{i j}^{\text {B3LYP/6-311+G** }}$. The force constants were furthermore modified by using the equation of $f_{i j}^{\text {scaled }}=$ $\left(c_{i} c_{j}\right)^{1 / 2} f_{i j}{ }^{\text {B3LYP/6-311+G** }}$ [20] where $c_{i}$ 's denote scale factors for force constants. Scale factors were derived by referring to wavenumber-linear scale factors reported in [14]: $c_{i}$ 's were 0.9197 for $\mathrm{C}-\mathrm{H}$ stretching coordinates whereas $c_{i}$ 's for other coordinates were 0.9841. The scaled force constants were used to calculate mean amplitudes and 
shrinkage corrections, $r_{\alpha}-r_{a}$, [21] required for the analysis of GED data.

Table 3 compares observed vibrational wavenumbers with calculated ones in the range of 1250 to $400 \mathrm{~cm}^{-1}$ which is useful to investigate conformation of DEMA. Three bands at about 773, 762 and $749 \mathrm{~cm}^{-1}$ observed in the gas and liquid phases are unambiguously assigned to the $t \mathrm{t}, \mathrm{g}^{+} \mathrm{t}$ and $\mathrm{g}^{-} \mathrm{t}$ conformers, respectively. The existence of the $\mathrm{g}^{+} \mathrm{g}^{+}$form in the gas phase is uncertain since no bands can be assigned solely to this form. However, Table 1 suggests that the stability of this form is similar to that of the $\mathrm{g}^{-} \mathrm{t}$ form. Therefore, the $\mathrm{g}^{+} \mathrm{g}^{+}$conformer seems to be present in the gas phase. On the other hand, the Raman and IR spectra of the liquid show the bands at 408 and 978 $\mathrm{cm}^{-1}$, which are assigned to the $\mathrm{g}^{+} \mathrm{g}^{+}$conformer. Therefore, the vibrational bands in the liquid phase are apparently interpreted in terms of coexistence of the four conformers.

\subsection{Analysis of gas electron diffraction data}

The following assumptions were made: (1) The model consisting of the tt, $g^{+} t, g^{-} t$ and $\mathrm{g}^{+} \mathrm{g}^{+}$conformers were adopted and the result is discussed later. (2) The $\mathrm{N}-\mathrm{C}, \mathrm{C}-\mathrm{C}$ and $\mathrm{C}-\mathrm{H}$ bond lengths, and $\mathrm{CNC}$ and NCC bond angles were refined in groups and differences in each group were fixed at the differences derived from B3LYP/6-311++G(2df,p) calculations. (3) The $\mathrm{NCH}$ and $\mathrm{CCH}_{\mathrm{Me}}$ bond angles were refined in one group and differences in the group were taken from B3LYP/6-311++G(2df,p) calculations. (4) The NCCH, C2NC3H, C2NC6H, C3NC2H, C3NC2C4 $\left(\phi_{1}\right)$ and C2NC3C5 $\left(\phi_{2}\right)$ dihedral angles were fixed at B3LYP/6-311++G(2df,p) values except for $\phi_{1}$ and $\phi_{2}$ of the tt conformer. The dihedral angles around the $\mathrm{N}-\mathrm{C}_{\mathrm{Et}}$ bonds of this conformer were refined by assuming the $C_{s}$ symmetry $\left(\phi_{1}=-\phi_{2}\right)$. (5) Mean amplitudes were refined in four groups as shown in 
Table 4. Groups were separated at 1.8, 2.8 and $3.55 \AA$ so that each group corresponds to one or more separated peaks of the experimental radial distribution curve (Fig. 3). The differences in each group were fixed at the calculated values. (6) Asymmetry parameters were estimated by the conventional methods [22].

Adjustable structural parameters, $r(\mathrm{~N}-\mathrm{C}), r(\mathrm{C}-\mathrm{C}), r(\mathrm{C}-\mathrm{H}), \angle \mathrm{CNC}, \angle \mathrm{NCC}, \angle \mathrm{NCH}$ and $\phi_{1}(\mathrm{tt})$, abundances of conformers, $X(\mathrm{tt}), X\left(\mathrm{~g}^{+} \mathrm{t}\right)$ and $X\left(\mathrm{~g}^{-} \mathrm{t}\right)$, mean amplitudes $l_{1}-l_{4}$ and indices of resolution for long- and short-camera distances, $k_{1}$ and $k_{\mathrm{s}}$, were determined by the least-squares calculations on molecular scattering intensities. There are no significant differences between refined and calculated mean amplitudes as shown in footnote of Table 4. Table 5 lists the structural parameters and conformational composition of DEMA obtained by GED. Correlation matrix elements [23] with absolute values larger than 0.6 are: $X(\mathrm{tt}) / X\left(\mathrm{~g}^{+} \mathrm{t}\right)=-0.61,\langle r(\mathrm{~N}-\mathrm{C})>/\langle r(\mathrm{C}-\mathrm{C})\rangle=-0.83$, $<r(\mathrm{~N}-\mathrm{C})>/ l_{1}=0.62,<r(\mathrm{C}-\mathrm{C})>/ l_{1}=-0.62$.

The mean amplitudes were calculated from the scaled force constants using the small-amplitude vibrational model. The validity of the model and force field used in this work can be roughly evaluated by comparing the calculated amplitudes with those obtained from GED data. The differences between the calculated and observed amplitudes are comparable to three times the standard errors (see Table 4), suggesting that the small-amplitude model and the scaled force field are reasonable for DEMA.

\section{Discussion}

Fig. 3 shows differences between the experimental radial distribution curve and the curves calculated by assuming one-conformer model. These differences indicate that any model consisting of one conformer is not acceptable. The conformational 
composition of DEMA was determined by GED to be $35(14) \% \mathrm{tt}+27(14) \% \mathrm{~g}^{+} \mathrm{t}+$ $20(17) \% \mathrm{~g}^{-} \mathrm{t}+18(23) \% \mathrm{~g}^{+} \mathrm{g}^{+}$with the $R$-factor of 0.039 (see the footnote $a$ of Table 5 for the definition). The value is much smaller than those of one-conformer models, $0.086(\mathrm{tt}), 0.078\left(\mathrm{~g}^{+} \mathrm{t}\right), 0.105\left(\mathrm{~g}^{-} \mathrm{t}\right)$ and $0.098\left(\mathrm{~g}^{+} \mathrm{g}^{+}\right)$. GED could not identify the existence of the $\mathrm{g}^{+} \mathrm{g}^{+}$conformer with certainty. By taking into account the multiplicity of the $t t, \mathrm{~g}^{+} \mathrm{t}, \mathrm{g}^{-} \mathrm{t}$ and $\mathrm{g}^{+} \mathrm{g}^{+}$conformers (1, 2, 2 and 2, respectively), it is found that the $\mathrm{tt}$ conformer is the most stable.

To examine the dependence of the experimental results on theoretical constraints included in the assumptions, the B3LYP/6-311++G(2df,p) constraints were compared with the corresponding values derived from the structures at the other levels of theory, which are deposited as supplementary data. Large differences were found for the MP2/6-311 $+\mathrm{G}^{* *}$ values of $\phi_{2}$ of the $\mathrm{g}^{+} \mathrm{t}, \mathrm{g}^{-} \mathrm{t}$ and $\mathrm{g}^{+} \mathrm{g}^{+}$conformers: these values (-174.2, -164.5 and $57.9^{\circ}$ ) are smaller than the B3LYP/6-311++G(2df,p) values by 10.0, 6.3 and $5.6^{\circ}$, respectively, whereas the remaining values of $\phi_{1}$ and $\phi_{2}$ are equal to the B3LYP/6-311++G(2df,p) values within $5^{\circ}$. The analysis where $\phi_{1}$ and $\phi_{2}$ of the $\mathrm{g}^{+} \mathrm{t}$, $\mathrm{g}^{-} \mathrm{t}$ and $\mathrm{g}^{+} \mathrm{g}^{+}$conformers were fixed at the MP2/6-311+G ${ }^{* *}$ values resulted in the conformational composition close to the above result: $38 \% \mathrm{tt}+23 \% \mathrm{~g}^{+} \mathrm{t}+18 \% \mathrm{~g}^{-} \mathrm{t}+$ $21 \% \mathrm{~g}^{+} \mathrm{g}^{+}$with the $R$-factor of 0.039 . Therefore, the constraints from the theoretical calculations do not significantly affect the experimental results.

Table 3 shows that the vibrational bands of the liquid are assigned to the four conformers. Vibrational analysis of the hydrocarbon analogue, 3-methylpentane, in the liquid phase identifies the conformers corresponding to the $t t, g^{+} t, g^{-} t$ and $g^{+} g^{+}$of DEMA [24, 25]. Crocker and Goggin [6] suggested that two bands in the IR and Raman spectra of the solid DEMA, 776 and $762 \mathrm{~cm}^{-1}$, were assigned to two conformers, 
tt and $\mathrm{g}^{+} \mathrm{t}$. In the present study, the assignments were confirmed by the vibrational analysis aided with the B3LYP/6-311+G ${ }^{* *}$ calculations. The above discussion on conformational analysis of DEMA indicates that the $t$ and $\mathrm{g}^{+} \mathrm{t}$ conformers are more stable than the $\mathrm{g}^{-} \mathrm{t}$ and $\mathrm{g}^{+} \mathrm{g}^{+}$conformers. The conformational stability of DEMA can be explained in terms of the number of trans CNCC fragments as follows: Two CNCC fragments of the $\mathrm{tt}$ and $\mathrm{g}^{+} \mathrm{t}$ conformers take trans conformation whereas one fragment is trans for the $\mathrm{g}^{-} \mathrm{t}$ and $\mathrm{g}^{+} \mathrm{g}^{+}$conformers.

In diethylamine [7], $\mathrm{tt}$ and $\mathrm{g}^{+} \mathrm{t}$ forms exist exclusively (42(16)\% $\mathrm{tt}+53(24) \% \mathrm{~g}^{+} \mathrm{t}+$ 5(20)\% $\mathrm{g}^{+} \mathrm{g}^{+}$) and the former is more stable than the latter. The $\mathrm{g}^{-} \mathrm{t}$ form is not detected in diethylamine. The difference in diethylamine and DEMA indicates that steric interaction between C6-methyl and ethyl groups is an important factor determining conformational stability of DEMA.

For $N$-chloro- $N$-ethylethanamine [8], the $\mathrm{tt}$ and $\mathrm{g}^{+} \mathrm{t}$ conformers exist with the populations of $68(8) \%$ and $32(8) \%$, respectively. It is well known that a methyl group has nearly the same size as a chlorine atom. Therefore, it may not be justified to ascribe the absence of $\mathrm{g}^{-} \mathrm{t}$ and $\mathrm{g}^{+} \mathrm{g}^{+}$conformers in gaseous $\mathrm{N}$-chloro- $\mathrm{N}$-ethylethanamine to the steric repulsion and more feasible explanation seems to be possible by means of the electronegativity of $\mathrm{Cl}$. The substitution of the chlorine atom by the methyl group decreases the stability of the $\mathrm{tt}$ and $\mathrm{g}^{+} \mathrm{t}$ conformers relative to the $\mathrm{g}^{-} \mathrm{t}$ and $\mathrm{g}^{+} \mathrm{g}^{+}$ conformers.

Our study on triethylamine [7] shows that CCNCC moieties take tt, $\mathrm{g}^{+} \mathrm{t}, \mathrm{g}^{-} \mathrm{t}$ and $\mathrm{g}^{+} \mathrm{g}^{+}$ conformations. Therefore, the $\mathrm{g}^{-} \mathrm{g}^{+}$conformation is not observed in diethylamine, DEMA and triethylamine. This is ascribable to steric repulsion between terminal methyl groups in the $\mathrm{g}^{-} \mathrm{g}^{+}$conformation. 


\section{Acknowledgments}

We thank the Computer Center, Institute for Molecular Science, Okazaki National Research Institutes, for the use of the NEC HPC and Fujitsu VPP5000 computers and GAUSSIAN 98. Numerical computations were carried out on a Hitachi Model MP5800/160 at the Hokkaido University Computing Center.

\section{Supplementary data}

Supplementary data associated with this article (tables of the leveled total intensities and the backgrounds, and the structures derived from the HF/6-31G ${ }^{* *}, \mathrm{MP} 2 / 6-31 \mathrm{G}^{* *}$, MP2/6-311+G** B3LYP/6-31G ${ }^{* *}$ and B3LYP/6-311+G ${ }^{* *}$ calculations) can be found in the online version. 


\section{References}

[1] Y. Hamada, M. Tsuboi, K. Yamanouchi, K. Kuchitsu, J. Mol. Struct. 146 (1986) 253.

[2] J. R. Durig, D. A. C. Compton, J. Phys. Chem. 83 (1979) 2873.

[3] G. Gamer, H. Wolff, Spectrochim. Acta, 29A (1973) 129.

[4] J. H. M. ter Brake, V. Mom, F. C. Mijlhoff, J. Mol. Struct. 65 (1980) 303.

[5] J. R. Durig, F. O. Cox, J. Mol. Struct. 95 (1982) 85.

[6] C. Crocker. P. L. Goggin, J. Chem. Soc. Dalton Trans. (1978) 388.

[7] H. Takeuchi, T. Kojima, T. Egawa, S. Konaka, J. Phys. Chem. 96 (1992) 4389.

[8] N. Kuze, H. Takeuchi, T. Egawa, S. Konaka, S. Q. Newton, L. Schäfer, J. Mol. Struct., 291 (1993) 11.

[9] C. H. Bushweller, S. H. Fleischman, G. L. Grady, P. McGoff, C. D. Rithner, M. R. Whalon, J. G. Brennan, R. P. Marcantonio, R. P. Domingue, J. Am. Chem. Soc. 104 (1982) 6224.

[10] SDBSWeb: http://www.aist.go.jp/RIODB/SDBS/ (National Institute of Advanced Industrial Science and Technology, 1993).

[11] C. Møller, M. S. Plesset, Phys. Rev. 46 (1934) 618.

[12] A. D. Becke, J. Chem. Phys. 98 (1993) 5648.

[13] C. Lee, W. Yang, R.G. Parr, Phys. Rev. B37 (1988) 785.

[14] H. Yoshida, A. Ehara, H. Matsuura, Chem. Phys. Lett. 325 (2000) 477.

[15] S. Konaka, M. Kimura, 13th Austin Symposium on Gas Phase Molecular Structure, The University of Texas, Austin, TX, 12-14 March 1990, S21.

[16] A. Tsuboyama, A. Murayama, S. Konaka, M. Kimura, J. Mol. Struct. 118 (1984) 351. 
[17] H. Takeuchi, J. Enmi, M. Onozaki, T. Egawa, S. Konaka, J. Phys. Chem. 98 (1994) 8632.

[18]. A.W. Ross, M. Fink and R. Hilderbrandt, J. Wang, V. H. Smith Jr. in: A.J.C. Wilson (Ed.), International Tables for X-Ray Crystallography, Kluwer Academic Publishers, Dordrecht, Boston and London, 1995 Vol. C, p. 245.

[19] M. J. Frisch, G. W. Trucks, H. B. Schlegel, G. E. Scuseria, M. A. Robb, J. R. Cheeseman, V. G. Zakrzewski, J. A. Montgomery Jr., R. E. Stratmann, J. C. Burant, S. Dapprich, J. M. Millam, A. D. Daniels, K. N. Kudin, M. C. Strain, O. Farkas, J. Tomasi, V. Barone, M. Cossi, R. Cammi, B. Mennucci, C. Pomelli, C. Adamo, S. Clifford, J. Ochterski, G. A. Petersson, P. Y. Ayala, Q. Cui, K. Morokuma, D. K. Malick, A. D. Rabuck, K. Raghavachari, J. B. Foresman, J. Cioslowski, J. V. Ortiz, A. G. Baboul, B. B. Stefanov, G. Liu, A. Liashenko, P. Piskorz, I. Komaromi, R. Gomperts, R. L. Martin, D. J. Fox, T. Keith, M. A. Al-Laham, C. Y. Peng, A. Nanayakkara, M. Challacombe, P. M. W. Gill, B. Johnson, W. Chen, M. W. Wong, J. L. Andres, C. Gonzalez, M. Head-Gordon, E. S. Replogle, J. A. Pople, Gaussian 98 (Revision A.9), Gaussian Inc., Pittsburgh, PA, 1998.

[20] J. E. Boggs, in I. Hargittai, M. Hargittai (Eds.). Stereochemical Applications of Gas-phase Electron Diffraction, VCH, New York, 1988 Part B, Ch. 10.

[21] K. Kuchitsu, S. J. Cyvin, in S. J. Cyvin (Ed.). Molecular Structures and Vibrations, Elsevier, Amsterdam, 1972, Ch. 12.

[22] K. Kuchitsu, L. S. Bartell, J. Chem. Phys. 35 (1961) 1945.

[23] I. Hargittai, in I. Hargittai, M. Hargittai (Eds.), Stereochemical Applications of Gas-phase Electron Diffraction, VCH, New York, 1988 Part A, Ch. 1. 
[24] G. A. Crowder, D. Hill, J. Mol. Struct. 145 (1986) 69.

[25] N. G. Mirkin, S. Krimm, J. Mol. Struct. 550-551 (2000) 67. 
Table 1

Calculated relative energies and populations of five conformers of diethylmethylamine

\begin{tabular}{|c|c|c|c|c|c|c|c|c|c|c|}
\hline & \multicolumn{5}{|c|}{ Relative energy / kJ mol ${ }^{-1}$} & \multicolumn{5}{|c|}{ Population / \% } \\
\hline & $\mathrm{tt}^{\mathrm{a}}$ & $g^{+} t$ & $g^{-t}$ & $\mathrm{~g}^{+} \mathrm{g}^{+}$ & $\mathrm{g}^{-} \mathrm{g}^{+}$ & $\mathrm{tt}$ & $g^{+} t$ & $\mathrm{~g}^{-} \mathrm{t}$ & $g^{+} g^{+}$ & $g^{-} g^{+}$ \\
\hline $\mathrm{RHF} / 6-31 \mathrm{G}^{* *}$ & 0.0 & 0.2 & 1.8 & 2.9 & 10.7 & 22.4 & 41.2 & 22.0 & 14.1 & 0.3 \\
\hline $\mathrm{MP} 2 / 6-31 \mathrm{G}^{* *}$ & 0.0 & 0.5 & 2.5 & 2.5 & 12.6 & 24.5 & 40.1 & 17.7 & 17.5 & 0.1 \\
\hline $\mathrm{MP} 2 / 6-311+\mathrm{G}^{* *}$ & 0.0 & 0.6 & 4.7 & 3.9 & 15.6 & 30.4 & 47.6 & 9.2 & 12.8 & 0.1 \\
\hline B3LYP/6-31G & 0.0 & 0.6 & 2.8 & 3.5 & 9.9 & 26.9 & 42.1 & 17.4 & 13.1 & 0.5 \\
\hline B3LYP/6-311+G** & 0.0 & 0.5 & 4.3 & 4.9 & 12.4 & 30.7 & 49.6 & 11.0 & 8.6 & 0.2 \\
\hline \multicolumn{11}{|c|}{ B3LYP/6-311++G(2df, p) } \\
\hline & 0.0 & 0.6 & 4.4 & 5.1 & 12.6 & 31.3 & 50.0 & 10.5 & 8.0 & 0.2 \\
\hline
\end{tabular}

${ }^{a}$ Total energies of RHF/6-31G ${ }^{* *}, \mathrm{MP} 2 / 6-31 \mathrm{G}^{* *}, \mathrm{MP} 2 / 6-311+\mathrm{G}^{* *}$, B3LYP/6-31G ${ }^{* *}$, B3LYP/6-311+G ${ }^{* *}$ and B3LYP/6-311++G(2df,p) calculations are -251.35802 $E_{\mathrm{h}}$, $-252.26771 E_{\mathrm{h}},-252.36227 E_{\mathrm{h}},-253.12006 E_{\mathrm{h}},-253.17728 E_{\mathrm{h}}$ and $-253.18745 E_{\mathrm{h}}$, respectively. 
Table 2

Bond lengths $(\AA)$, bond angles and dihedral angles $\left(^{\circ}\right)$ of diethylmethylamine calculated at the B3LYP/6-311++G(2df,p) level

\begin{tabular}{|c|c|c|c|c|c|}
\hline parameter $^{\text {a }}$ & $\mathrm{tt}$ & $g^{+} t$ & $g^{-} t$ & $\mathrm{~g}^{+} \mathrm{g}^{+}$ & $\mathrm{g}^{-} \mathrm{g}^{+}$ \\
\hline$r(\mathrm{~N} 1-\mathrm{C} 2)$ & 1.46 & 1.464 & 1.462 & 1.460 & 1.454 \\
\hline$r(\mathrm{~N} 1-\mathrm{C} 3)$ & 1.46 & 1.463 & 1.460 & 1.463 & 1.454 \\
\hline$r(\mathrm{~N} 1-\mathrm{C} 6)$ & 1.45 & 1.455 & 1.453 & 1.453 & 1.447 \\
\hline$r(\mathrm{C} 2-\mathrm{C} 4)$ & 1.52 & 1.525 & 1.536 & 1.525 & 1.539 \\
\hline$r(\mathrm{C} 3-\mathrm{C} 5)$ & 1.52 & $1.52 €$ & 1.527 & 1.537 & 1.539 \\
\hline$\angle \mathrm{C} 2 \mathrm{~N} 1 \mathrm{C} 3$ & 111.4 & 112.6 & 113.9 & 115.7 & 118.3 \\
\hline$\angle \mathrm{C} 2 \mathrm{~N} 1 \mathrm{C} 6$ & 112.1 & 111.0 & 113.4 & 111.9 & 115.7 \\
\hline$\angle \mathrm{C} 3 \mathrm{~N} 1 \mathrm{C} 6$ & 112.1 & 112.0 & 113.7 & 113.3 & 115.7 \\
\hline$\angle \mathrm{N} 1 \mathrm{C} 2 \mathrm{C} 4$ & 113.9 & 113.9 & 117.2 & 113.9 & 118.3 \\
\hline$\angle \mathrm{N} 1 \mathrm{C} 3 \mathrm{C} 5$ & 113.9 & 113.8 & 113.3 & 117.1 & 118.3 \\
\hline$\phi(\mathrm{C} 3 \mathrm{~N} 1 \mathrm{C} 2 \mathrm{C} 4)$ & 165.3 & 72.4 & -66.0 & 60.3 & -81.0 \\
\hline$\phi(\mathrm{C} 6 \mathrm{~N} 1 \mathrm{C} 2 \mathrm{C} 4)$ & -68.2 & -161.2 & 66.1 & -167.9 & 62.9 \\
\hline$\phi(\mathrm{C} 2 \mathrm{~N} 1 \mathrm{C} 3 \mathrm{C} 5)$ & -165.3 & -163.3 & -158.2 & 63.5 & 80.7 \\
\hline$\phi(\mathrm{C} 6 \mathrm{~N} 1 \mathrm{C} 3 \mathrm{C} 5)$ & 68.2 & 70.7 & 69.8 & -67.6 & -63.2 \\
\hline
\end{tabular}

${ }^{a}$ The structural parameters including hydrogen atoms are omitted for simplicity. 
Table 3

Observed and calculated wavenumbers $\left(\mathrm{cm}^{-1}\right)$ and potential energy distributions (PED) for diethylmethylamine ${ }^{\mathrm{a}}$

\begin{tabular}{lll} 
Obs & Calc & PED(\%) \\
\hline $\mathrm{IR}^{\mathrm{b}}$ & Raman $^{\mathrm{b}} \mathrm{IR}^{\mathrm{c}}$ & \\
Gas & liquid liquid &
\end{tabular}

1244sh

1252, $1253 \quad g^{+} \mathrm{t}[\mathrm{b}(27)], \mathrm{g}^{-} \mathrm{t}[\mathrm{b}(21)]$

$1239 m$

1245

$\mathrm{tt}[\mathrm{b}(27)]$

$1232 \mathrm{~m}$

12351233

$\mathrm{tt}[\mathrm{S}(22), \mathrm{b}(22), \mathrm{P}(21)]$

$1227 m$

12271230

$\mathrm{g}^{-} \mathrm{t}[\mathrm{P}(26), \mathrm{b}(23)]$

1218sh

12211225

$\mathrm{g}^{+} \mathrm{t}[\mathrm{P}(23), \mathrm{S}(22), \mathrm{b}(22)]$

12171223

$\mathrm{g}^{+} \mathrm{g}^{+}[\mathrm{P}(29), \mathrm{b}(24)]$

$1208 m$

1207

1166sh

1169

$\mathrm{g}^{+} \mathrm{t}[\mathrm{b}(55), \mathrm{P}(22)]$

$1160 \mathrm{~m}$

1156 1165, 1159

$\mathrm{tt}[\mathrm{b}(52)], \mathrm{g}^{+} \mathrm{g}^{+}[\mathrm{b}(58)]$

1149sh

1149

$g^{-} \mathrm{t}[\mathrm{b}(58)]$

1117, 1113

tt[P(33),b(30)], g $\mathrm{g}^{+}[\mathrm{b}(61)]$

1110sh

1110

$g^{+} t[b(51)]$

1104sh

1106, 1107

$\mathrm{tt}[\mathrm{b}(52)], \mathrm{g}^{-} \mathrm{t}[\mathrm{b}(50)]$

1098m

11001099

$g^{+} t[b(36)]$

1094sh

10941096

$\mathrm{g}^{-} \mathrm{t}[\mathrm{b}(40)]$

1085sh

1090, 1091

$\mathrm{g}^{-} \mathrm{t}[\mathrm{b}(31)], \mathrm{g}^{+} \mathrm{g}^{+}[\mathrm{b}(37)]$ 
1070s

1077, 1076, 1077tt[b(56)], g t[b(45)], $\mathrm{g}^{+} \mathrm{g}^{+}[\mathrm{b}(43), \mathrm{S}(26)]$

1065s 1067m 1064 1071, 1069, 1071tt[R(48)], $g^{+} t[b(26), S(22)], g^{+} g^{+}[b(27), R(21)]$

1060s 1059sh 1058 1060, $1061 \quad g^{+} t[R(28), b(28)], g^{-} t[R(37)]$

$1049 \mathrm{~m}$

10471047

$\mathrm{tt}[\mathrm{R}(40), \mathrm{b}(30)]$

1040, $1035 \quad g^{+} g^{+}[R(42)], g^{-} t[R(29), b(21)]$

$994 m$

992 992, 993

$\mathrm{tt}[\mathrm{S}(33), \mathrm{b}(32)], \mathrm{g}^{+} \mathrm{t}[\mathrm{R}(46), \mathrm{S}(26)]$

978973

$\mathrm{g}^{+} \mathrm{g}^{+}[\mathrm{R}(55)]$

$970 \quad 967$

$g^{-} \mathrm{t}[\mathrm{R}(47), \mathrm{S}(21)]$

$908 w$

909w

910910,909

$\mathrm{tt}[\mathrm{R}(44)], \mathrm{g}^{+} \mathrm{t}[\mathrm{b}(30)]$

893, 891

$\mathrm{g}^{-} \mathrm{t}[\mathrm{R}(35), \mathrm{b}(24)], \mathrm{g}^{+} \mathrm{g}^{+}[\mathrm{R}(31), \mathrm{b}(31)]$

$811 w$

808 813, 811, 808

$\mathrm{tt}[\mathrm{b}(53), \mathrm{P}(51)], \mathrm{g}^{+} \mathrm{g}^{+}[\mathrm{b}(53), \mathrm{P}(49)]$,

$\mathrm{g}^{+} \mathrm{t}[\mathrm{P}(53), \mathrm{b}(51)]$

803, 805

$\mathrm{g}^{+} \mathrm{t}[\mathrm{P}(55), \mathrm{b}(51)], \mathrm{g}^{-} \mathrm{t}[\mathrm{P}(56), \mathrm{b}(52)]$

798

$\mathrm{tt}[\mathrm{P}(61), \mathrm{b}(50)]$

782, 779

$\mathrm{g}^{-} \mathrm{t}[\mathrm{P}(54), \mathrm{b}(51)], \mathrm{g}^{+} \mathrm{g}^{+}[\mathrm{P}(60), \mathrm{b}(52)]$

773m $\quad 774 m \quad 776 \quad 773$

$\mathrm{tt}[\mathrm{S}(76), \mathrm{b}(24)]$

762m 760m $761 \quad 759$

$\mathrm{g}^{+} \mathrm{t}[\mathrm{S}(70), \mathrm{b}(22)]$

749sh $\quad 747 \mathrm{~m} \quad 750 \quad 750$

$g^{-} \mathrm{t}[\mathrm{S}(75)]$

743

$\mathrm{g}^{+} \mathrm{g}^{+}[\mathrm{S}(63)]$

525

$g^{-} \mathrm{t}[\mathrm{X}(59), \mathrm{b}(22), \mathrm{Y}(21)]$

494w $491 \quad 486,484,488$

$\mathrm{tt}[\mathrm{X}(62), \mathrm{Y}(44)], \mathrm{g}^{+} \mathrm{t}[\mathrm{X}(51), \mathrm{Y}(34)]$,

$\mathrm{g}^{+} \mathrm{g}^{+}[\mathrm{Y}(39), \mathrm{X}(57)]$

474

$\mathrm{g}^{+} \mathrm{g}^{+}[\mathrm{Y}(45), \mathrm{X}(38)]$

458s

450

$g^{+} t[Y(40), X(32)]$ 
$434 s$

426, 423

$\mathrm{tt}[\mathrm{Y}(31), \mathrm{X}(26)], \mathrm{g}^{-} \mathrm{t}[\mathrm{Y}(78)]$

408w

413

$\mathrm{g}^{+} \mathrm{g}^{+}[\mathrm{Y}(60)]$

${ }^{\mathrm{a}}$ Wavenumbers between 1250 and $400 \mathrm{~cm}^{-1}$ are listed. Abbreviations used: s, strong; m, medium; w, weak; sh, shoulder; R, C-C stretching; S, N-C stretching; b, methyl rocking; P, methylene rocking; X, NCC bending; Y, CNC bending. Contributions less than $20 \%$ were omitted. Calculated wavenumbers lower than $400 \mathrm{~cm}^{-1}$ are 384,356 , 270, 247, 203, 195, 81 and $77 \mathrm{~cm}^{-1}$ for tt, 397, 314, 287, 232, 218, 204, 100 and $70 \mathrm{~cm}^{-1}$ for $\mathrm{g}^{+} \mathrm{t}, 394,330,265,228,210,203,98$ and $85 \mathrm{~cm}^{-1}$ for $\mathrm{g}^{-} \mathrm{t}$, and 297, 285, 241, 224, 213, 133 and $76 \mathrm{~cm}^{-1}$ for $\mathrm{g}^{+} \mathrm{g}^{+}$, respectively. Calculated wavenumbers of $\mathrm{g} \mathrm{g}^{-}$form are: 1239, 1137, 1105, 1100, 1091, 1056, 1039, 950, 879, 791, 774, 731, 494, 444, 418, 312, 233, 232, 216, 197, 110 and $52 \mathrm{~cm}^{-1}$.

${ }^{\mathrm{b}}$ Present study.

${ }^{\mathrm{C}}$ Taken from the literature $[6,10]$. 
Table 4

Mean amplitudes $l_{i j}$ and interatomic distances $r_{a}$ of diethylmethylamine ( $\AA$ )

\begin{tabular}{|c|c|c|c|c|c|c|c|c|c|c|c|c|}
\hline \multicolumn{2}{|c|}{ Atom pair ${ }^{\mathrm{a}}$} & \multicolumn{2}{|l|}{$\mathrm{tt}$} & \multicolumn{3}{|c|}{$g^{+} t$} & \multicolumn{3}{|c|}{$g^{-} t$} & \multicolumn{3}{|c|}{$\mathrm{g}^{+} \mathrm{g}^{+}$} \\
\hline & $l_{i j}^{\text {obs }}$ & $r_{a}$ & $\mathrm{n}^{\prime}$ & ${ }^{\mathrm{b}} l_{i j}{ }^{\mathrm{obs}}$ & $r_{a}$ & $\mathrm{n}$ & $l_{i j}^{\text {obs }}$ & $r_{a}$ & & $l_{i j}^{\text {obs }}$ & $r_{a}$ & $\mathrm{n}^{\mathrm{D}}$ \\
\hline$<\mathrm{C}-\mathrm{H}>$ & 0.083 & 1.107 & 1 & 0.083 & 1.107 & 1 & 0.083 & 1.107 & 1 & 0.083 & 1.107 & 1 \\
\hline$<\mathrm{N}-\mathrm{C}>$ & 0.054 & 1.460 & 1 & 0.054 & 1.461 & 1 & 0.054 & 1.458 & 1 & 0.054 & 1.459 & 1 \\
\hline$<\mathrm{C}-\mathrm{C}>$ & 0.055 & 1.519 & 1 & 0.055 & 1.519 & 1 & 0.057 & 1.525 & 1 & 0.056 & 1.525 & 1 \\
\hline C2 $\cdots$ C3 & 0.076 & 2.404 & 2 & 0.075 & 2.420 & 2 & 0.073 & 2.434 & 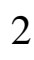 & 0.072 & 2.460 & 2 \\
\hline C $2 \cdots C 6$ & 0.075 & 2.404 & 2 & 0.077 & 2.390 & 2 & 0.073 & 2.420 & 2 & 0.076 & 2.398 & 2 \\
\hline С3…6 6 & 0.075 & 2.404 & 2 & 0.074 & 2.403 & 2 & 0.075 & 2.424 & 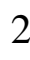 & 0.073 & 2.420 & 2 \\
\hline $\mathrm{N} 1 \cdots \mathrm{C} 4$ & 0.074 & 2.490 & 2 & 0.075 & 2.492 & 2 & 0.075 & 2.549 & 2 & 0.075 & 2.549 & 2 \\
\hline N1 ‥C5 & 0.074 & 2.490 & 2 & 0.074 & 2.484 & 2 & 0.074 & 2.480 & 2 & 0.074 & 2.491 & 2 \\
\hline C2 $\cdots$ C5 & 0.087 & 3.755 & 4 & 0.090 & 3.749 & 4 & 0.092 & 3.745 & 4 & 0.122 & 3.105 & 3 \\
\hline C3 $\cdots$ C4 & 0.087 & 3.755 & 4 & 0.115 & 3.072 & 3 & 0.130 & 3.094 & 3 & 0.111 & 3.009 & 3 \\
\hline C4 $\cdots$ C5 & 0.127 & 4.932 & 4 & 0.176 & 4.271 & 4 & 0.143 & 4.561 & 4 & 0.280 & 3.727 & 4 \\
\hline C4 $\cdots$ C6 & 0.130 & 2.991 & 3 & 0.090 & 3.732 & 4 & 0.125 & 3.053 & 3 & 0.084 & 3.755 & 4 \\
\hline C5 $\cdots$ C6 & 0.130 & 2.991 & 3 & 0.130 & 3.054 & 3 & 0.125 & 3.073 & 3 & 0.122 & 3.064 & 3 \\
\hline
\end{tabular}

${ }^{a}$ The mean amplitudes of relatively important atom pairs are listed. The bracket denotes an average value.

${ }^{\mathrm{b}}$ The mean amplitudes with the same number were refined as one group. Values of $l_{i j}{ }^{\text {obs }}-l_{\mathrm{ij}}^{\text {calc }}$ are $0.004(2), 0.005(3),-0.012(9)$ and $0.011(9) \AA$ for groups 1,2 3, and 4, 
respectively, where the numbers in parentheses are three times the standard errors from the least-squares refinement $3 \sigma$. 
Table 5

Structural parameters and conformational composition of diethylmethylamine ${ }^{\mathrm{a}}$

\begin{tabular}{|c|c|c|c|c|}
\hline Parameters & $\mathrm{tt}$ & $g^{+} t$ & $g^{-} t$ & $\mathrm{~g}^{+} \mathrm{g}^{+}$ \\
\hline$r_{\mathrm{g}}(\mathrm{N} 1-\mathrm{C} 2)$ & $1.465(2), r_{1}^{b}$ & b $\quad 1.466\left(r_{1}\right)^{\mathrm{c}}$ & $1.464\left(r_{1}\right)^{\mathrm{c}}$ & $1.462\left(r_{1}\right)^{\mathrm{C}}$ \\
\hline$r_{\mathrm{g}}(\mathrm{N} 1-\mathrm{C} 3)$ & $1.465\left(r_{1}\right)^{\mathrm{c}}$ & $1.465\left(r_{1}\right)^{\mathrm{C}}$ & $1.462\left(r_{1}\right)^{\mathrm{c}}$ & $1.465\left(r_{1}\right)^{\mathrm{C}}$ \\
\hline$r_{\mathrm{g}}(\mathrm{N} 1-\mathrm{C} 6)$ & $1.457\left(r_{1}\right)^{\mathrm{c}}$ & $1.457\left(r_{1}\right)^{\mathrm{C}}$ & $1.455\left(r_{1}\right)^{\mathrm{C}}$ & $1.455\left(r_{1}\right)^{\mathrm{C}}$ \\
\hline$r_{\mathrm{g}}(\mathrm{C} 2-\mathrm{C} 4)$ & $1.521(3), r_{2}$ & $2^{b} 1.521\left(r_{2}\right)^{c}$ & $1.532\left(r_{2}\right)^{\mathrm{c}}$ & $1.521\left(r_{2}\right)^{c}$ \\
\hline$r_{\mathrm{g}}(\mathrm{C} 3-\mathrm{C} 5)$ & $1.521\left(r_{2}\right)^{\mathrm{C}}$ & $1.522\left(r_{2}\right)^{\mathrm{C}}$ & $1.523\left(r_{2}\right)^{\mathrm{C}}$ & $1.533\left(r_{2}\right)^{\mathrm{c}}$ \\
\hline$\angle \alpha \mathrm{C} 2 \mathrm{~N} 1 \mathrm{C} 3$ & $110.5(5), \theta_{1}^{\mathrm{b}}$ & $111.7\left(\theta_{1}\right)^{\mathrm{c}}$ & $113.0\left(\theta_{1}\right)^{\mathrm{c}}$ & $114.8\left(\theta_{1}\right)^{\mathrm{c}}$ \\
\hline$\angle_{\alpha} \mathrm{C} 2 \mathrm{~N} 1 \mathrm{C} 6$ & $111.2\left(\theta_{1}\right)^{\mathrm{c}}$ & $110.1\left(\theta_{1}\right)^{\mathrm{c}}$ & $112.5\left(\theta_{1}\right)^{\mathrm{c}}$ & $111.0\left(\theta_{1}\right)^{\mathrm{c}}$ \\
\hline$\angle{ }_{\alpha} \mathrm{C} 3 \mathrm{~N} 1 \mathrm{C} 6$ & $111.2\left(\theta_{1}\right)^{\mathrm{c}}$ & $111.1\left(\theta_{1}\right)^{\mathrm{c}}$ & $112.8\left(\theta_{1}\right)^{\mathrm{c}}$ & $112.4\left(\theta_{1}\right)^{\mathrm{c}}$ \\
\hline$\angle{ }_{\alpha} \mathrm{N} 1 \mathrm{C} 2 \mathrm{C} 4$ & $114.0(5), \theta_{2}^{b}$ & $114.0\left(\theta_{2}\right)^{\mathrm{c}}$ & $117.3\left(\theta_{2}\right)^{\mathrm{c}}$ & $114.0\left(\theta_{2}\right)^{\mathrm{c}}$ \\
\hline$\angle{ }_{\alpha} \mathrm{N} 1 \mathrm{C} 3 \mathrm{C} 5$ & $114.0\left(\theta_{2}\right)^{\mathrm{c}}$ & $113.9\left(\theta_{2}\right)^{\mathrm{c}}$ & $113.4\left(\theta_{2}\right)^{\mathrm{c}}$ & $117.2\left(\theta_{2}\right)^{\mathrm{c}}$ \\
\hline$\phi_{1}(\mathrm{C} 3 \mathrm{~N} 1 \mathrm{C} 2 \mathrm{C} 4)$ & $170(4)$ & $72.4^{\mathrm{e}}$ & $-66.0^{\mathrm{e}}$ & $60.3^{\mathrm{e}}$ \\
\hline$\phi_{2}(\mathrm{C} 2 \mathrm{~N} 1 \mathrm{C} 3 \mathrm{C} 5)$ & $-170^{\mathrm{d}}$ & $-163.3^{e}$ & $-158.2^{\mathrm{e}}$ & $63.5^{\mathrm{e}}$ \\
\hline Abundance/\% & $35(14)$ & $27(14)$ & 20(17) & 18(23) \\
\hline
\end{tabular}

a Bond lengths in $\AA$ and angles in degrees. The structural parameters averaged over the conformers are: $\langle r(\mathrm{~N}-\mathrm{C})\rangle=1.462(2),\langle r(\mathrm{C}-\mathrm{C})\rangle=1.523(3),\langle r(\mathrm{C}-\mathrm{H})\rangle=1.113(2)$, $<\angle \mathrm{CNC}>=111.6(5),<\angle \mathrm{NCC}>=114.5(5),<\angle \mathrm{NCH} / \angle \mathrm{CCH}_{\mathrm{Me}}>=110.6(5)$, where $<>$ denotes an average value. The numbers in parentheses are $3 \sigma$, where $\sigma$ denotes the standard error from the least-squares refinement. Indices of resolutions for short- and 
long-camera distances are $0.92(1)$ and $0.92(2)$, respectively. The $R$-factor defined by the equation of $R=\left\{\sum_{i} W_{i}\left(s M(s)_{i}{ }^{\text {obs }}-s M(s)_{i}{ }^{\text {calc }}\right)^{2} / \Sigma_{i} W_{i}\left(s M(s)_{i}{ }^{\text {obs }}\right)^{2}\right\}^{1 / 2}$ is 0.039 where $W_{i}$ is a diagonal element of the weight matrix. ${ }^{\mathrm{b}} r_{i}$ and $\theta_{i}$ denote independent parameters. ${ }^{\mathrm{c}}$ Dependent on $r_{i}$ or $\theta_{i} . \quad{ }^{\mathrm{d}}$ Depentent on C3N1C2C4. ${ }^{\mathrm{e}}$ Fixed at the B3LYP/6-311++G(2df,p) values. 


\section{Figure captions}

Fig. 1. Molecular model of diethylmethylamine. The letters $\mathrm{t}, \mathrm{g}^{+}$and $\mathrm{g}^{-}$are used to indicate that dihedral angles C4C2N1C3 and C5C3N1C2 are approximately 180, 60 and $-60^{\circ}$, respectively.

Fig. 2. Experimental molecular scattering intensities (dots) and theoretical ones (solid lines) of diethylmethylamine with the composition of $35 \% \mathrm{tt}+27 \% \mathrm{~g}^{+} \mathrm{t}+20 \% \mathrm{~g}^{-} \mathrm{t}+$ $18 \% \mathrm{~g}^{+} \mathrm{g}^{+} ; \Delta s M(s)=s M(s)^{\mathrm{obs}}-s M(s)^{\mathrm{calc}}$.

Fig. 3. Experimental radial distribution curve of diethylmethylamine; $\Delta f(r)=f(r)^{\text {exp }}-$ $f(r)^{\text {theor }}$. The pairs listed in Table 4 are indicated by vertical bars. The difference curves $\Delta f(r)$ between the experimental curve and curves calculated by assuming that one conformer exists with its abundance of $100 \%$ are also shown. 


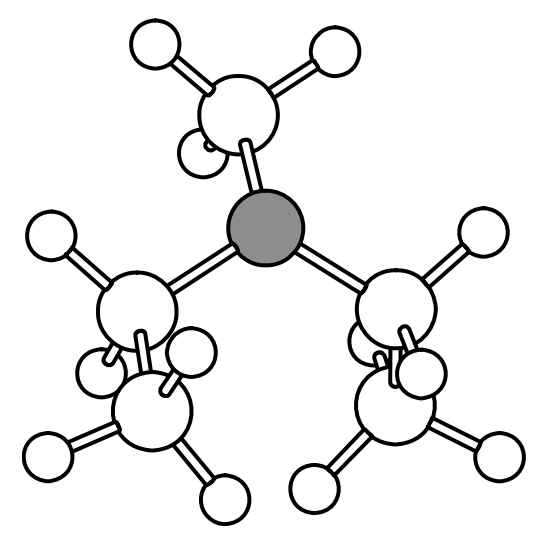

$\mathrm{g}^{+} \mathrm{g}^{+}$

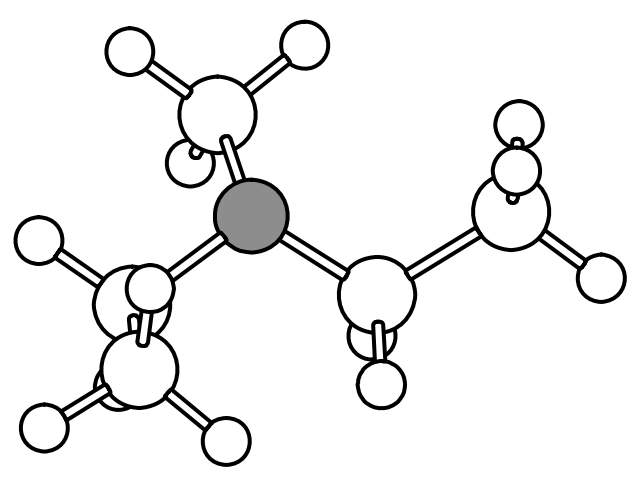

$g^{+} t$

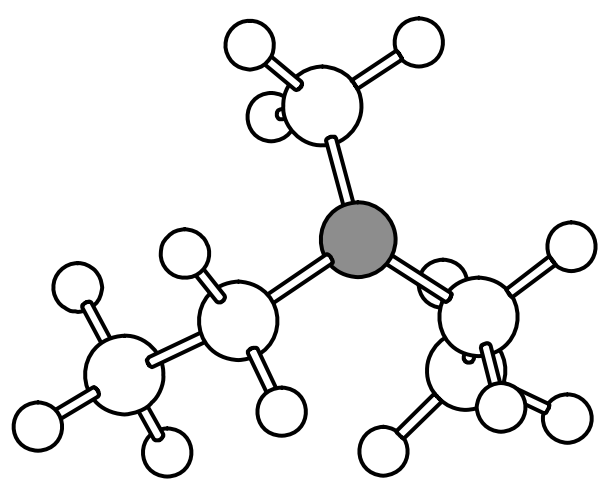

$\mathrm{g}^{-} \mathrm{g}^{+}$

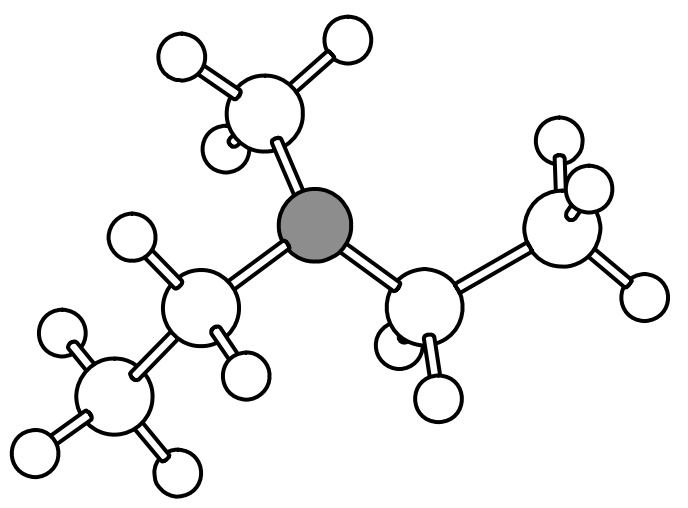

$\mathrm{g}^{-} \mathrm{t}$

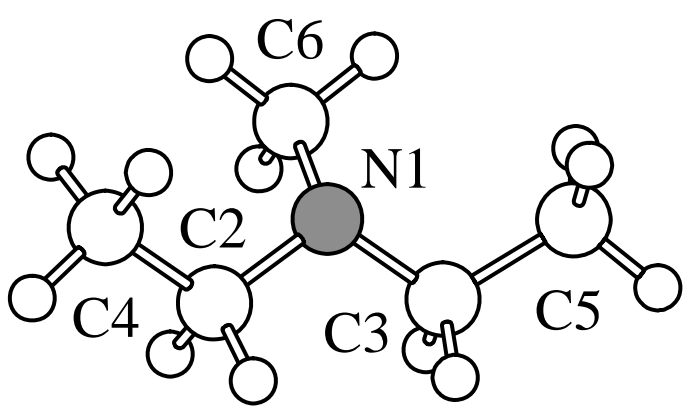

tt

Fig. 1. Takeuchi et al., Molecular structure and conformation of diethylmethylamine determined by gas electron diffraction and vibrational spectroscopy combined with theoretical calculations 


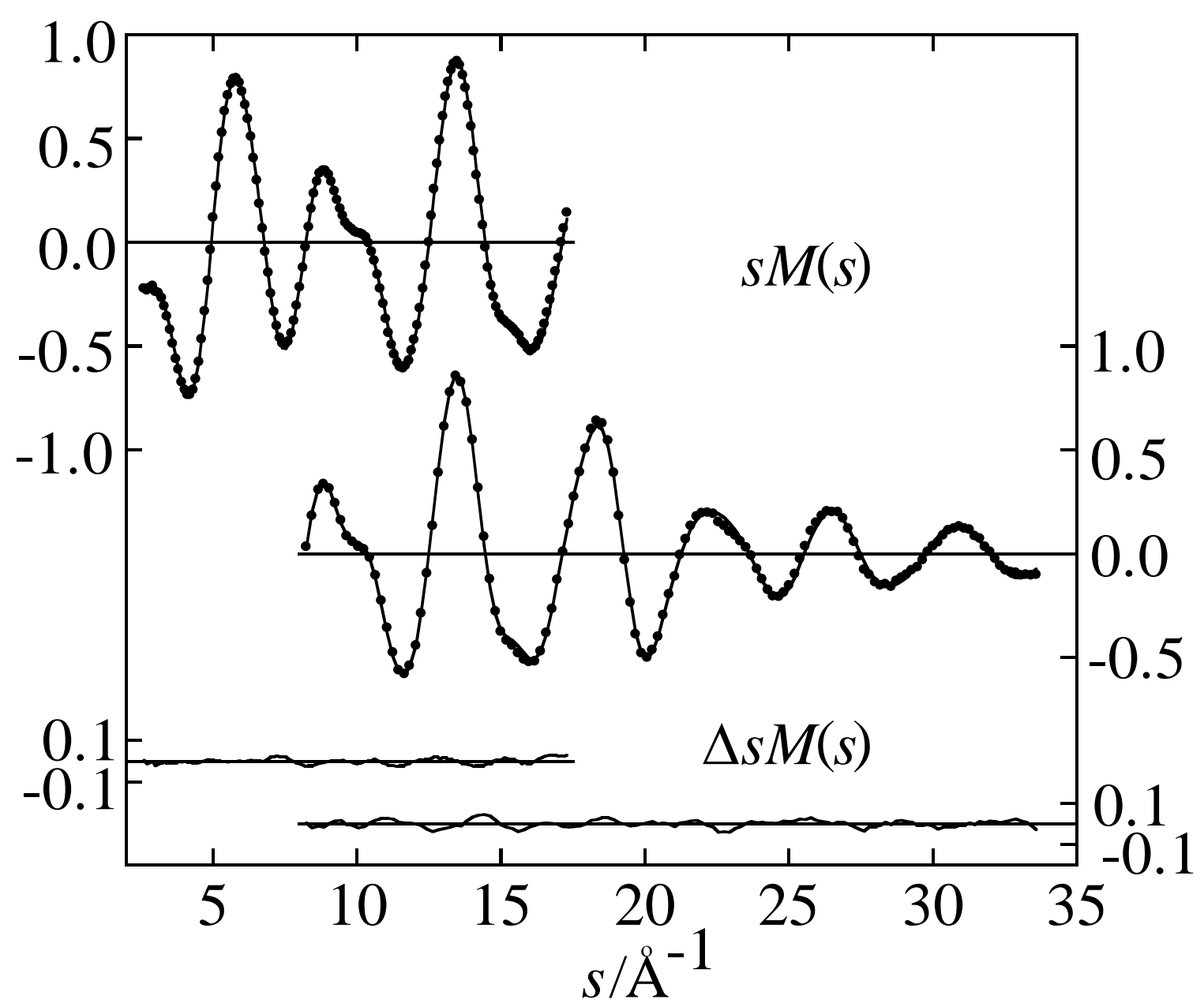

Fig. 2. Takeuchi et al., Molecular structure and conformation of diethylmethylamine determined by gas electron diffraction and vibrational spectroscopy combined with theoretical calculations 


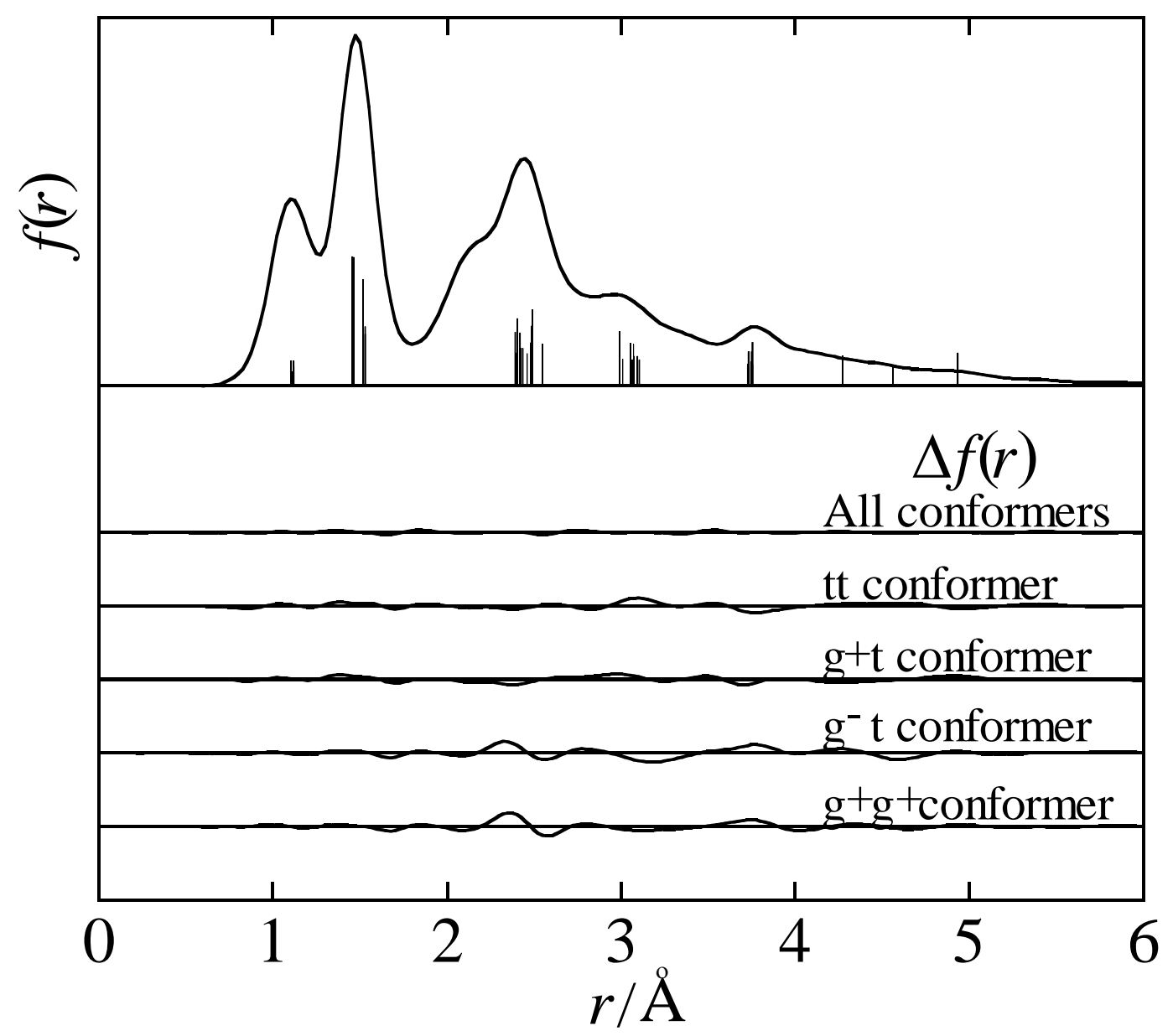

Fig. 3. Takeuchi et al., Molecular structure and conformation of diethylmethylamine determined by gas electron diffraction and vibrational spectroscopy combined with theoretical calculations 